\title{
UPTAKE OF MODERATELY HYDROPHOBIC CHLOROPHENOLS FROM WATER BY SEMIPERMEABLE MEMBRANE DEVICES (SPMDs) AND BY GOLDFISH
}

\author{
(Crassius auratus)
}

\author{
Yi Wang, Chunxia Wang and Zijian Wang \\ State Key Laboratory of Environmental Aquatic Chemistry, Research Center for Eco-Environmental \\ Sciences, Chinese Academy of Sciences, Beijing, 100085, P. R. China \\ (Received in Germany 2 September 1997; accepted 12 February 1998)
}

\begin{abstract}
Semipermeable membrane devices (SPMDs) filled with triolein and goldfish (Crassius auratus) were simultaneously exposed to nine moderately hydrophobic chlorophenols in a laboratory continuousflow experiment. The results showed that the tested compounds were concentrated in the device to an extent very closed to that in fish. The overall uptake rate constants $\left(K_{u}\right)$ and average pollutant sampling rates $\left(R_{s}\right)$ were similar for both SPMDs and goldfish. We conclude that the SPMDs can be used to estimate the levels of moderately hydrophobic chlorophenols in field water as an environmental monitor. C1998 Elsevier Science Ltd. All rights reserved
\end{abstract}

Key Words: SPMDs, Fish, Chlorophenols

\section{Introduction}

Semipermeable membrane device (SPMD) is a new tool for passive, in situ monitoring concentrations of organics in the aquatic environment $(1,2,3)$. In SPMDs, the mechanism behind the uptake of chemicals is based on the process of passive partitioning of a compound between water and a thin film of neutral lipid, enclosed in a semipermeable polymeric membrane. Therefore SPMDs can be used to mimic the uptake process by which aquatic organisms concentrate hydrophobic organic contaminants from water $(2,4,5)$. In SPMDs, triolein, which constitutes a significant fraction of the lipid pool of most aquatic organisms (6), is generally used as the lipid phase. Polyethylene is generally used as the semipermeable membrane (Triolein-SPMD).

* Author to whom all correspondence should be addressed. 
Since the beginning of the 1990s, SPMDs have drawn more and more attention in the monitoring of hydrophobic pollutants in the water and air. It has been used to study a variety of organic compounds, mostly the highly hydrophobic contaminants such as PAHs, PCBs, organochlorine insecticides, and pyrethroid insecticides $(4,5,10-15)$. These compounds have all been shown to be concentrated in SPMDs in a manner similar to aquatic organisms. However, less work has been done for moderately and weakly hydrophobic compounds.

In this study, nine chlorophenols of moderately hydrophobic contaminants and of great importance to environment were selected as model compounds in a laboratory continuous-flow experiment, in order to study the uptake of the compounds by goldfish (Crassius auratus) and SPMDs simultaneously.

\section{Experimental Section}

\section{Chemicals, SPMDs and Fish}

4-chlorophenol(4-CP), 2,3-dichlorophenol(2,3-DCP), 3,4-dichlorophenol(3,4-DCP), 3,5-dichlorophenol(3,5-DCP), 2,3,4-trichlorophenol(2,3,4-TCP), and 3,4,5-trichlorophenol(3,4,5-TCP) (purity of then was 95-97\%) were purchased from Beijing Chemical Company. 2-chlorophenol(2-CP), 2,4dichlorophenol(2,4-DCP), 2,4,6-trichlorophenol(2,4,6-TCP) (purity of them was $95-99 \%$ ) were purchased from Sigma Chemical Company (St. Louis, USA). The nine chlorophenols are important pollutants from pulp industry and are widely applied as pesticides, which have resulted in severe pollution in many rivers around the world.

Semipermeable membrane device was prepared in a similar way as described by Huckins et al.(1). Layflat polyethylene tubing (width $3.0 \mathrm{~cm}$, membrane thickness $50 \mu \mathrm{m}$, from Beijing Plastics Company) was cut into pieces of $15 \mathrm{~cm}$ in length, soaked in cyclohexane for $24 \mathrm{~h}$ to remove trace contaminants, and dried with ultra pure nitrogen. Then $20 \mu \mathrm{J}(18.2 \mathrm{mg}$ ) of high purity triolein $(99 \%)$, purchased from Sigma Chemical Company, was coated onto the inner part of the polyethylene tubing $(14 \mathrm{~cm})$ before the ends were sealed with a plastic sealer (Model SF-300. Lianyungang Microwave Electric Appliance Factory, China). The tube was formed into twisted loops and glass sticks were used as anchors to keep the device in a vertical position when suspended in the test solution. 
Goldfish (Crassius auratus, 6 months) were obtained from Guanyuan Aquatic Institute in Beijing. The average lengths and weights of the fish were $9.5( \pm 2.3) \mathrm{cm}$ and $7.9( \pm 2.7) \mathrm{g}$, respectively. The average lipid content calculated on fresh weight was $2.37( \pm 0.72) \%$. The fish were sterilized in $5 \%(w / v)$ salt water for 5 minutes and reared under the laboratory condition for two weeks before experiment. The death rate during the domestication was lower than $2 \%$.

\section{Flow-through experiment}

40 SPMDs and 50 goldfish were placed in an exposure chamber (volume 70 liters). A concentrated mixture of the nine chlorophenols was added at a constant rate $\left(1 \mathrm{mlmin}^{-1}\right)$ into the main water flow to the chamber by a peristaltic pump. The overall flow rate through the exposure chamber was maintained at $20 \mathrm{mlmin}^{-1}$ and the rate of the peristaltic pump was adjusted to obtain relatively stable concentrations of the different chemicals in the exposure chamber (Table 1). The temperature in the exposure chamber was maintained at $20^{\circ} \mathrm{C}$, and $\mathrm{pH}$ at 6.0 which was lower than all the pKa values of the nine chlorophenols under testing. 12 goldfish and 12 SPMDs were placed in a control chamber with the same volume as the exposure chamber but without addition of chlorophenols, and maintained under the same conditions as described above. The experiment was conducted for 10 days. During the experiment, three SPMDs and four goldfish from the exposure chamber and one SPMD and one goldfish from the control chamber were sampled for analysis at $1,2,4,6,12,24,48,72,96,144,192$ and 240 hours of the exposure, respectively. To monitor the concentrations of the added compounds in the experimental chamber, triplicate samples of the water were taken every two days.

\section{Measurement of chlorophenols accumulated by SPMDs}

After sampling, the SPMDs were rinsed with distilled water, dried with clean paper, transferred into beakers containing $40 \mathrm{ml}$ of cyclohexane, and dialysed at $13^{\circ} \mathrm{C}$ for 24 hours. The SPMDs were removed and the solvent passed through anhydrous sodium sulfate and evaporated to dryness in a rotary evaporator and redissolved with $2 \mathrm{ml}$ of methanol. The chlorophenols were determined by a Shimadzu model LC-10AD high performance liquid chromatograph (HPLC) with a $5 \mu \mathrm{m}$ LiChrospher RPC18 column (LiChroCART). The HPLC was equipped with a SPD-M10A UV detector. Analysis conditions 
Table 1. Properties of the Studied Chlorophenols and Concentrations in the Exposure Chamber

\begin{tabular}{|c|c|c|c|c|}
\hline Compound & MW & $\mathrm{pKa}$ & $\log K_{o / w}$ & $\begin{array}{l}\text { Concentration in water } \\
\left(\mu \mathrm{g} \mathrm{l}^{-1}, \text { MeantSD }\right), \mathrm{n}=6\end{array}$ \\
\hline $2-\mathrm{CP}$ & 128.5 & $8.52^{\mathrm{a}}$ & $2.16^{\mathrm{c}}$ & $34.7 \pm 6.1$ \\
\hline 4-CP & 128.5 & $9.37^{\mathrm{a}}$ & $2.42^{\circ}$ & $25.7 \pm 3.7$ \\
\hline 2,3-DCP & 163.0 & $7.76^{\mathrm{b}}$ & $3.09^{b}$ & $33.0 \pm 11.6$ \\
\hline 2,4-DCP & 163.0 & $8.09^{b}$ & $3.17^{d}$ & $23.5 \pm 6.3$ \\
\hline 3,4-DCP & 163.0 & $8.68^{\mathrm{b}}$ & $3.38^{b}$ & $20.9 \pm 8.4$ \\
\hline 3,5-DCP & 163.0 & $8.27^{b}$ & $3.55^{b}$ & $16.3 \pm 2.4$ \\
\hline $2,4,6-\mathrm{TCP}$ & 197.5 & $6.21^{b}$ & $3.66^{\circ}$ & $3.3 \pm 2.8$ \\
\hline $2,3,5-\mathrm{TCP}$ & 197.5 & $6.43^{\mathrm{a}}$ & $3.55^{\prime \prime}$ & $1.6 \pm 0.8$ \\
\hline $3,4,5-\mathrm{TCP}$ & 197.5 & $7.81^{b}$ & $4.28^{\mathrm{b}}$ & $0.9 \pm 0.1$ \\
\hline
\end{tabular}

${ }^{a}$ Data cited from literature (16)

${ }^{\mathrm{b}}$ Data cited from literature (17).

${ }^{\mathrm{c}}$ Data cited from literature (18).

${ }^{\mathrm{d}}$ Data cited from literature (19).

Table 2. Estimated Uptake Kinetic Parameters for Chlorophenols in SPMDs.

\begin{tabular}{|c|c|c|c|c|c|c|}
\hline \multirow[t]{2}{*}{ Compound } & \multicolumn{2}{|c|}{$\mathrm{K}_{\mathrm{L} / \mathrm{W}}$} & \multicolumn{2}{|c|}{$\mathrm{K}_{\mathrm{u}}\left(\mathrm{hrs}^{-1}\right)$} & \multirow[t]{2}{*}{$r^{2}$} & \multirow[t]{2}{*}{$190 \%$ (hours) } \\
\hline & Estimate & $\mathrm{CV}^{\mathrm{b}}, \%$ & Estimate & $\mathrm{CV}^{\mathrm{b}}, \%$ & & \\
\hline $2-C P$ & 16.82 & 11.3 & 0.05 & 23.7 & 0.78 & 46.05 \\
\hline 4-CP & 43.51 & 14.8 & 1.13 & 28.9 & 0.77 & 2.04 \\
\hline $2,3-\mathrm{DCP}$ & 13.68 & 10.1 & 0.21 & 20.3 & 0.80 & 10.96 \\
\hline 2,4-DCP & 18.90 & 13.5 & 0.30 & 26.1 & 0.79 & 7.68 \\
\hline $3,4-\mathrm{DCP}$ & 42.75 & 8.2 & 0.16 & 16.8 & 0.84 & 14.39 \\
\hline 3,5-DCP & 173.35 & 6.1 & 0.34 & 11.3 & 0.87 & 6.77 \\
\hline $2,4,6-\mathrm{TCP}$ & 3113.46 & 5.2 & 0.16 & 10.2 & 0.89 & 14.39 \\
\hline $2,3,5-\mathrm{TCP}$ & 1590.26 & 12.8 & 0.88 & 27.5 & 0.77 & 2.62 \\
\hline $3,4,5-\mathrm{TCP}$ & 783.63 & 14.9 & 1.05 & 18.6 & 0.83 & 2.19 \\
\hline
\end{tabular}

${ }^{a}$ Time required to reach $90 \%$ equilibrium concentration in SPMDs.

${ }^{b} \mathrm{CV}$, variation coefficient $(\%)$. 
are: wavelength, $210 \mathrm{~nm}$; flowrate, $1 \mathrm{mlmin}^{-1}$; eluent, methanol-water-HAc (50:50:0.4 = v:v:v).

A spiking study was carried out for eight replicates at concentrations similar to those expected in the SPMD samples and showed that the recoveries for the chlorophenols after dialysis ranged from $63 \%$ to $75 \%$. The standard deviation did not exceed $10 \%$. The levels in the SPMDs were accordingly corrected for the loss during dialysis. The weight loss of triolein during the dialysis with cyclohexane were less than $1 \%$ and polyethylene waxes found in the solvent during the dialysis was negligible. Therefore, no further clean-up procedure was required before analysis.

\section{Determination of chlorophenols accumulated by the goldfish}

The fish were sacrificed and homogenized in a mortar with three times by weight of anhydrous sodium sulfate. $20 \mathrm{~g}$ of the mixture was placed in a Soxhlet apparatus and the chlorophenols were extracted with $30 \mathrm{ml}$ of acetone/petroleum ether mixture $(59: 41=\mathrm{v} / \mathrm{v})$ at $60-65^{\circ} \mathrm{C}$ for 2 hours. The extract was passed through a column of anhydrous sodium sulfate, then rotary evaporated to approximately $1 \mathrm{ml}$ and transferred into polyethylene tubings. The sealed plastic tubings were dialyzed in cyclohexane at $13^{\circ} \mathrm{C}$ for 24 hours. After removing the tubings, the solvent was passed through anhydrous sodium sulfate, rotary evaporated to dryness and redissolved with $2 \mathrm{ml}$ of methanol, then analyzed by HPLC as described earlier. The dialysis recoveries for 9 chlorophenols from goldfish in recovery studies were from $59 \%$ to $70 \%$ and the standard deviation of the averaged recovery did not exceed $15 \%$. To estimate the concentrations of chemicals in the lipid of goldfish, the measured values were corrected for loss during the dialysis by the correction coefficients derived from the recovery studies.

\section{Measurement of chlorophenols in water}

The tested compounds were extracted with $2 \mathrm{ml}$ of cyclohexane from the water. The extract was evaporated to dryness with ultra pure nitrogen and redissolved with $2 \mathrm{ml}$ of methanol, then analyzed with HPLC as described earlier. A spiking study was carried out for eight replicates at concentrations similar to those expected in the exposure chamber and the results showed that recoveries of the chemicals were in the range of $93-104 \%$. Therefore, no correction for losses was necessary for this analytical step. 


\section{Results and Discussion}

\section{Uptake of the chlorophenols by SPMDs and goldfish in flow-through experiment}

The moderately hydrophobic chlorophenols were taken up very fast by the SPMDs (Fig. 1). After 12 hours, a steady state was achieved with device concentration factors (DCFs, ratio of concentration of compound in triolein of SPMD to concentration in water) ranging from 15 to 3000 . Bioconcentration factors (BCFs, ratio of concentration of compound in lipid of fish to concentration in water) were similar to or higher than DC'Fs for the chlorophenols tested, except for 2,4,6-Irichlorophenol, which shows much lower than the correspondent DCF. Comparison of the partition coefficients for SPMD/water( $\left.\log \mathrm{K}_{\mathrm{L} / w}\right)$, for fish/water $(\log B C F)$, and partition coefficients for octanol/water $\left(\log K_{O / W}\right)$ showed that the three factors were closely correlated for the nine chlorophenols(Fig. 2).

\section{Uptake kinetics}

An kinetic equation proposed by Huckins et al.(2) based on a two-compartments bioconcentration model was used to describe the overall uptake curves of the chemicals accumulated in SPMDs (equation 1). The same equation was used also to describe accumulation of those chemicals in goldfish.

$$
C_{l}=C_{W} K_{L: W}\left(1-e^{-k_{W} i}\right)
$$

where $C_{L}$ is the concentration of a chemical in the SPMD; $C_{W}$ is the concentration in water; $K_{L W}$ is the lipid/water partition coefficient; and $K_{u}$ is the overall uptake rate constant. $K_{L W}$ and $K_{u}$ were estimated through fitting the experimental data using the SPSS 6.0 software for Windows and its LevenbergMarquardt least-squares algorithm, with $t$ and $C_{l}$ being independent and dependent variable respectively, and $C_{W}$ being constant.

A good fit of the experimental data to the kinetic equation (1) was obtained for all the chemicals, either concentrated by SPMD or by goldfish. The squared $r$ values for the regressions ranged from 0.75 to 0.89 . Variations for coefficients $K_{L} \mu$ and $K_{u}$ for SPMD were less than $15 \%$ and $30 \%$, respectively. Variations for coefficients $K_{L W}$ and $K_{u}$ for goldfish were less than $20 \%$ and $25 \%$, respectively (Table 2 and 3). Based on the $K_{L W}$ and $K_{u}$ values, we have calculated the time required to reach $90 \%$ steady-state concentration in SPMD and in goldfish, respectively (Table 2,3). The uptake of the tested moderately hydrophobic compounds reached this level in SPMDs within 50 hours, in fish within 15 hours. 

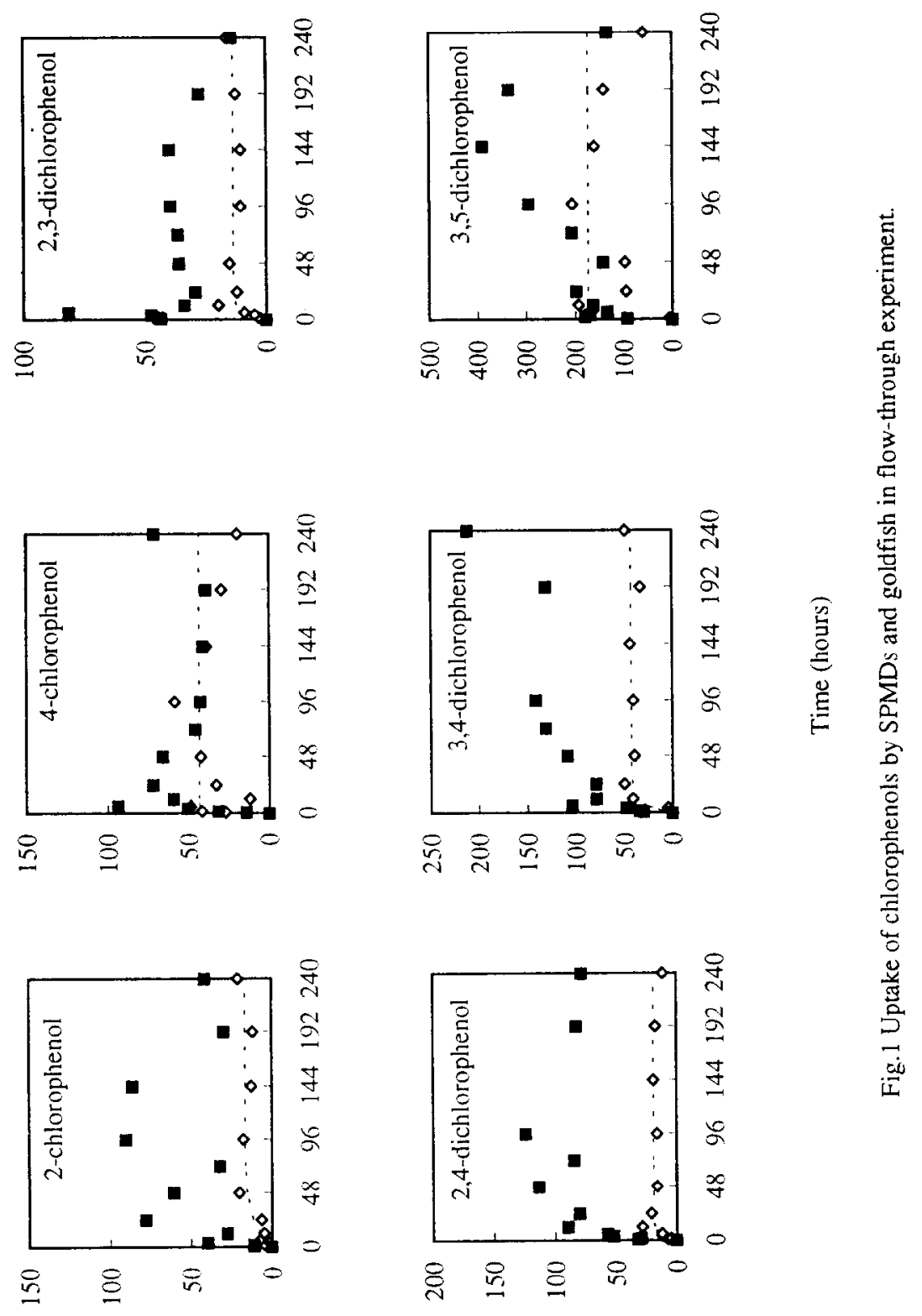

(a) ปวด pur (a) ปวด

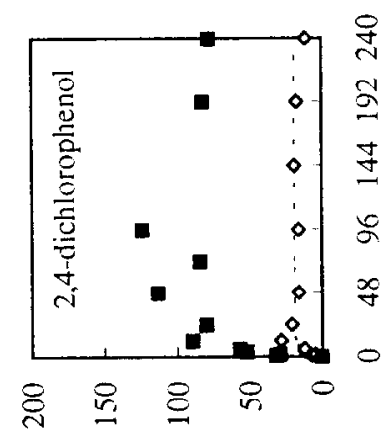

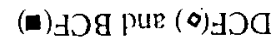



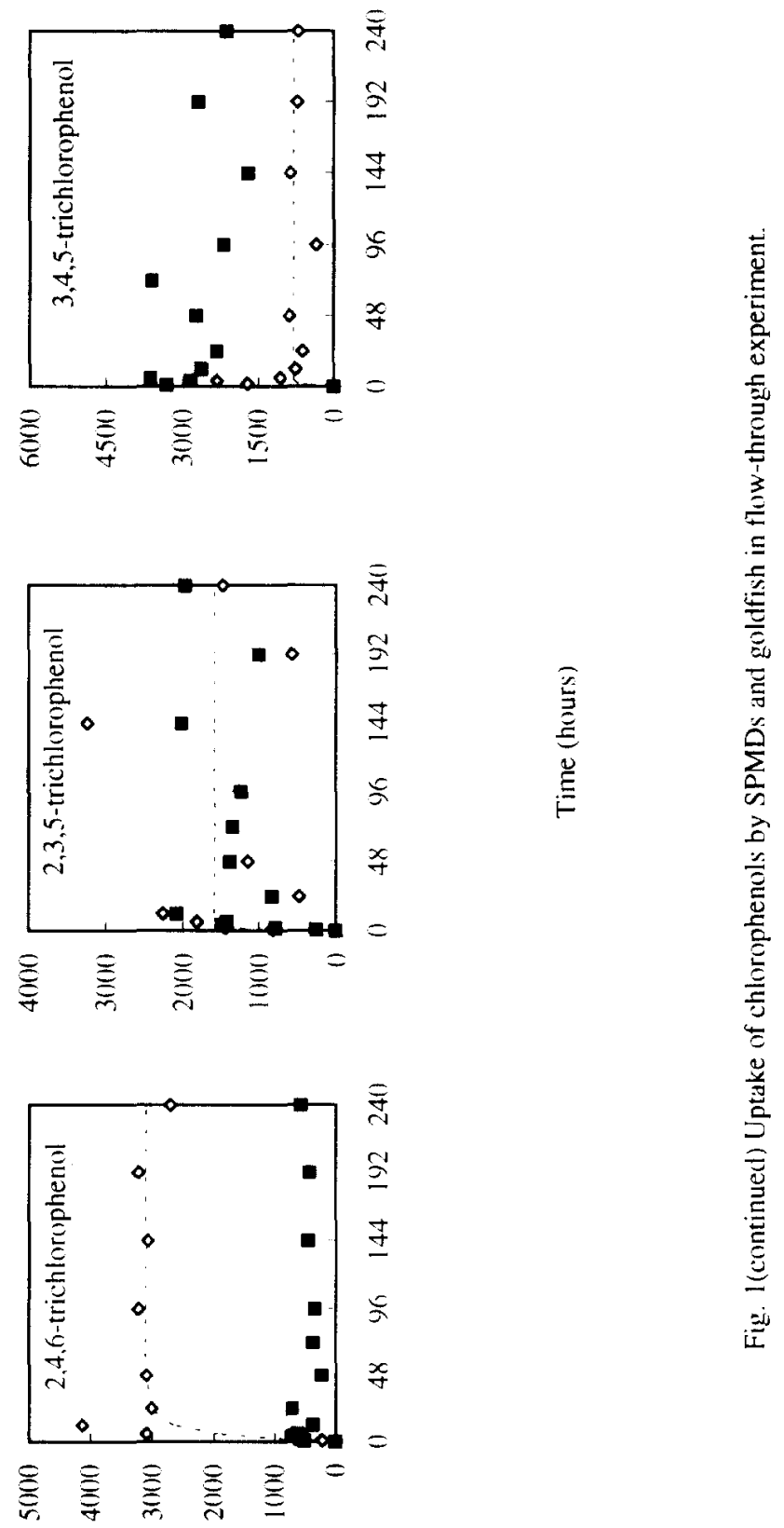

葛

(๔) JDg pur (๑) 


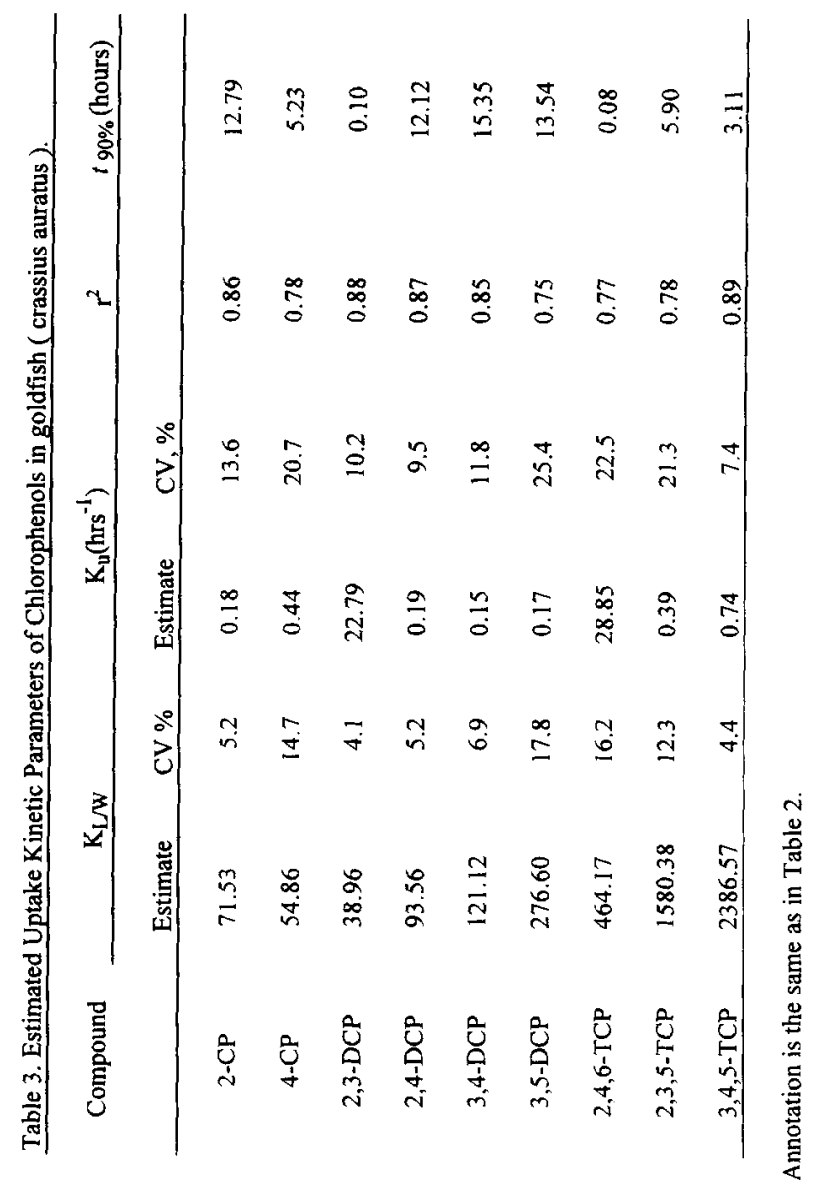




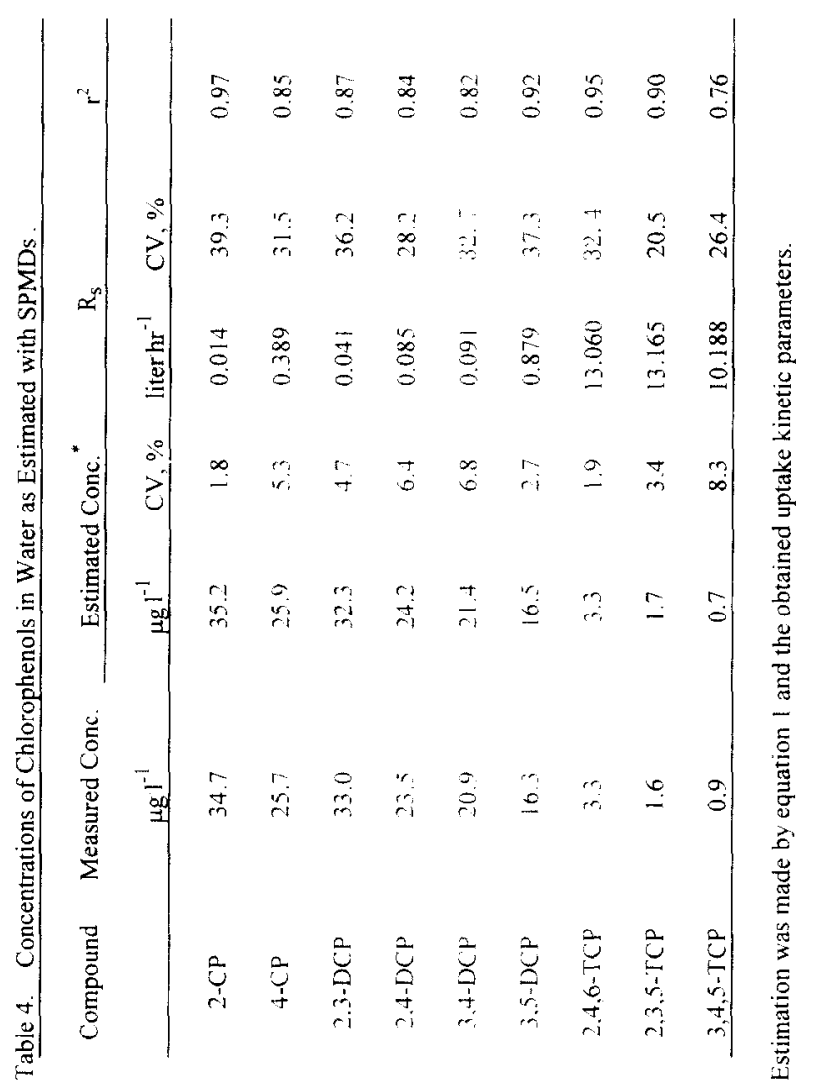




\section{Prediction of chemical concentrations in water}

The $K_{L W W}$ and $K_{u}$ were used in equation (1) to estimate the concentrations of chlorophenols in SPMDs and in goldfish based on their concentration in the water or vice versa (Fig. 1 and Table 4). The estimated concentration in the water were close to the measured average water concentrations with variation coefficients not exceeding $10 \%$ at steady-state (Table 4). Therefore we conclude that SPMD can be used to predict concentrations of moderately hydrophobic chlorophenols in water.

Another parameter used to predict chemical concentrations in water by SPMDs is the sampling rate $\mathbf{R}_{\mathrm{s}}$, which could be used in the linear uptake kinetics region. To obtain the $\mathbf{R}_{\mathbf{s}}$, a mathematical model was used to fit the experimental data (2). In the model, the concentration of a chemical in the SPMDs $\left(C_{L}\right)$ should be proportional to the sampling rate $\left(R_{s}\right)$ of SPMD when it is linearly proportional to the concentration of the chemical in water (equation 2).

$$
C_{L}=\frac{C_{W} R_{s} t}{V_{L}}
$$

where $V_{L}$ is the volume of the triolein used in the SPMD; $R_{s}$ is the sampling rate of the SPMD, expressed as extracted volumes of water per hour and is specific for different chemicals; and $t$ is the sampling time.

Equation (2) was fitted by least squares linear regression to the linear portion of the experimental data for the SPMDs and for goldfish. A good fit was obtained for all chemicals with $r$ squared values from 0.76 to 0.97 in the linear regression. Variation coefficients for $R_{s}$ were less than $39 \%$ (Table 4 ). By definition, $R_{\mathrm{S}}$ is indicative for the potentiality of a chemical entering the SPMD, which in turn depends on both device parameters and the ability of a chemical to be absorbed by the polyethylene membrane $\left(R_{s}=K_{M} / w \cdot k_{0} \cdot A\right.$, where $K_{M} / w$ is the distribution coefficient of a chemical between membrane and water, $k_{0}$ is overall membrane mass-transfer coefficient and $A$ is membrane surface area (11).

\section{Conclusion}

We conclude that SPMD may be used to sequester trace chlorophenols from water effectively, though they are less lipophobic. A comparison between chemicals concentrated in SPMDs and in fish demonstrate that SPMD has the similar uptake potential as fish has, and may be used to sample moderately hydrophobic chlorophenols from field water as an environmental monitor less expensively. 


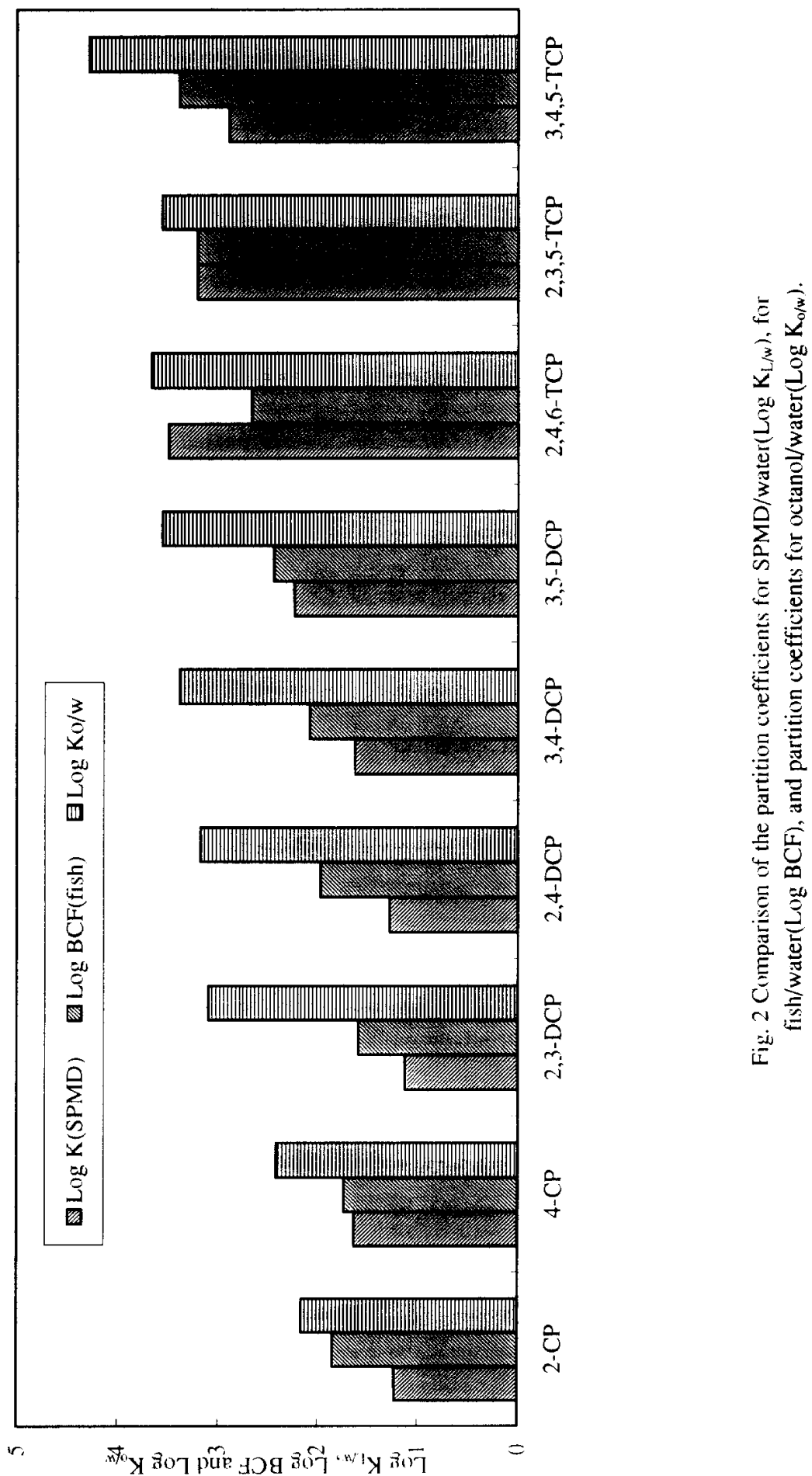




\section{Acknowledgments}

This paper was supported by National Nature Science Foundation Project 29637010 . Thanks are due to Prof. Anders Sodergren in the Department of Ecology, Lund University, Sweden for careful revise the manuscript

\section{Literature Cited}

(1) Huckins, J.N., Tubergen, M.W. and Manuweera, G.K., Chemosphere, 1990, 20, 5, 533-552.

(2) Huckins, J.N., Manuweera, G.K., Petty, J.D., et al., Environ. Sci. Technol, 1993, 27, 2489- 2496.

(3) Sodergren A., Environ. Sci. Technol, 1987, 21, 9, 855-859.

(4) Lebo, J.A., Gale, R.W., Petty, J.D., et al., Environ. Sci. Technol, 1995, 29, 2886-2892.

(5) Lebo, J.A., Zajicek, J.L., Huckins, J.N., et al., Chemosphere, 1992, 25, 5,697-718.

(6) Ellis, G.S., Huckins, J.N., Rostad, C.E., et al., Environ. Toxicol. Chem., 1995, 14, 11, 1875-1884.

(7) Prest, H.F., Jarman, W.M., Burns, S.A., et al., Chemosphere, 1992, 25, 1811-1823.

(8) Chiou, C.T., Environ. Sci. Technol, 1992, 19, 57-62.

(9) Bennett, E.R., Metcalfe, T.L. and Metcalfe, C.D., Chemosphere, 1996, 33, 363-375.

(10) Gale, R., Huckins, J.N., Meadows, J., et al., 3rd Ann. SPMD Workshop, 1995, Midwest Science Center, Columbia, Missouri.

(11) Petty, J.D., Huckins, J.N. and Zajicek, J.L., Chemosphere, 1993, 27, 9, 1609-1624.

(12) Prest, H.F. and Jacobson, L.A., Chemosphere, 1995, 30, 7, 1351-1361.

(13) Peven, C.S., Uhler, A.D. and Querzoli, F.J., Environ. Toxicol. Chem., 1996, 15, 2, 141-149.

(14) Prest, H.F., Huckins, J.N., Petty, J.D., et al., Environmental Pollution, 1997, 94, 2, 244-245.

(15) Moring, J.B. and Rose, D.R., Chemosphere, 1997, 34, 3, 551-566.

(16) Drahohovsky J. and Vacek Z., Czechoslov. Chem. Commun., 1971, 36, 3431-3440.

(17) Xie T. M. and Dyrssen D., Analytica Chimica Acta, 1984, 160, 21-30.

(18) Hanai T. and Hubert J., HRC\&CC, 1983, 6, 20-26.

(19) Xie T. M., Hulthe B. and Folestad S., Chemosphere, 1984, 13, 445-460. 